\title{
The Hidden Burden of Diabetes Mellitus in an Urban Community of Southwest Ethiopia
}

This article was published in the following Dove Press journal:

Diabetes, Metabolic Syndrome and Obesity: Targets and Therapy

\author{
Temamen Tesfaye Yunka (iD \\ Solomon Berhanu Mogas $\mathbb{D}^{2}$ \\ Belay Zawdie ${ }^{3}$ \\ Dessalegn Tamiru (iD) ${ }^{4}$ \\ Yonas Tesfaye $\mathbb{D D}^{5}$ \\ Ayantu Kebede ${ }^{2}$ \\ Mulualem Tadesse 6 \\ Esayas Kebede Gudina ${ }^{7}{ }^{7}$ \\ Lelisa Sena Dadi ${ }^{2}$ \\ 'School of Nursing and Midwifery, Jimma \\ University, Jimma, Oromia Region, \\ Ethiopia; ${ }^{2}$ Department of Epidemiology, \\ Jimma University, Jimma, Oromia Region, \\ Ethiopia; ${ }^{3}$ Department of Biomedical \\ Sciences, Jimma University, Jimma, \\ Oromia Region, Ethiopia; ${ }^{4}$ Department of \\ Nutrition and Dietetics, Jimma University, \\ Jimma, Oromia Region, Ethiopia; \\ ${ }^{5}$ Department of Psychiatry, Jimma \\ University, Jimma, Oromia Region, \\ Ethiopia; ${ }^{6}$ Department of Medical \\ Laboratory, Jimma University, Jimma, \\ Oromia Region, Ethiopia; ${ }^{7}$ Department of \\ Internal Medicine, Jimma University, \\ Jimma, Oromia Region, Ethiopia
}

Introduction: Early detection of the unrecognized diabetes mellitus (DM) and its risk factors in the community is crucial to minimizing the burden of DM and associated complications. Hence, this study aimed to assess unrecognized DM and its relationship with behavioral characteristics, physical characteristics, and lipid profile among adults in Jimma Town, Southwest Ethiopia.

Methods: A community-based cross-sectional study was conducted on 915 adults in Jimma Town from June 17 to July 27, 2019. Physical measurements, lipid profile, and blood sugar levels were measured. The collected data were entered and analyzed using Epi Data 3.1 and SPSS version 21, respectively. Multivariable logistic regression was fitted to assess predictors of unrecognized DM where adjusted odds ratio (AOR) with its corresponding 95\% confidence interval (CI) was used to assess the strength of association at P-value $\leq 05$.

Results: The prevalence of unrecognized DM and impaired glucose metabolism (prediabetes) were $3.1 \%$ (95\% CI; 2.0-4.4) and 14.8\% (95\% CI; 12.5-17.2), respectively. The risk of unrecognized DM was higher among male participants (AOR = 2.94, 95\% CI: 1.19, 7.29 ), age group of 35 years and above $(\mathrm{AOR}=3.45,95 \% \mathrm{CI}: 1.16,10.27)$, and high waist circumference $(\mathrm{AOR}=4.21,95 \% \mathrm{CI}: 1.72,10.33)$. On the other hand, participants who perform sufficient physical activity $(\mathrm{AOR}=0.14,95 \% \mathrm{CI}: 0.03,0.58)$ had low risk of undetected DM.

Conclusion: The prevalence of unrecognized diabetes mellitus was relatively high. Male sex, advanced age, physical inactivity, and high waist circumference were found to be predictors of unrecognized DM. Thus, awareness needs to be created among the community to practice regular physical activity and maintaining normal body weight. Additionally, screening of DM should be promoted for early detection, prevention, and treatment.

Keywords: unrecognized DM, diabetes mellitus, adult, lipid profile, physical measurement

\section{Introduction}

Diabetes mellitus (DM) is a metabolic disorder characterized by high blood glucose levels due to either decreases the production of insulin or resistance of the body to insulin. The three main types of diabetes are type 1 diabetes (T1D), type 2 diabetes (T2D), and gestational DM (GDM). ${ }^{1}$ Individuals with DM have a higher risk of developing several serious life-threatening complications resulting in reduced quality of life, increased medical care costs, and mortality. ${ }^{2,3}$ The morbidity, mortality, and burden related to diabetes are significantly increasing in developing countries particularly in Africa. These are due to sedentary lifestyles, growing urbanization cultures, decreased physical activities, and increased alcohol use, smoking habit, and dietary changes. ${ }^{4}$
Correspondence: Temamen Tesfaye Yunka School of Nursing and Midwifery, Jimma University, P.O.Box-378, Oromia region, Ethiopia

Tel +251913153299

Email tekanetesfu@gmail.com 
Globally, the prevalence of diabetes has intensified widely. According to the International Diabetes Federation (IDF), the estimated 463 million (9.3\%) adults aged 20-79 years had diabetes in 2019. It is predicted that the number will increase to 578 million $(10.2 \%)$ and 700 million (10.9\%) in 2030 and 2045 respectively. ${ }^{5}$ Similarly, the World Health Organization (WHO) projected that diabetes will be the seventh leading cause of death by $2030 .{ }^{6}$ Sadly, more than half $(50.1 \%)$ of people with DM are unaware of their disease and most of them $(84.3 \%)$ were found in low and middle-income countries. In Africa, nearly $60 \%$ of all people living with diabetes were undiagnosed. ${ }^{5,7}$

In sub-Saharan Africa, the burden of DM among adults aged 20-79 years was estimated to be 10.8 million with four countries alone: South Africa, Nigeria, DR Congo, and Ethiopia; accounting for about $60 \%$ of all adults living with DM in the region. ${ }^{7}$ Ethiopia is one of the top countries with the highest number of people affected by DM in Africa. ${ }^{8}$ According to the 2017 IDF report, the prevalence of DM among adults aged $18-99$ years was $4.8 \%$ and total diabetes-related death was 31,536 . Moreover, about twothirds of adults with diabetes mellitus has been reported to be undiagnosed in the country. ${ }^{9}$

There are different factors for the high rate of undiagnosed DM for many years, which includes lack of awareness in the general population and health care providers, poor health systems and slow onset of the symptoms. ${ }^{10,11}$ Late diagnosis and treatment of DM are associated with the increased occurrence of acute and chronic complications. ${ }^{12}$ Subsequently, this affects patients' quality of life, ${ }^{13}$ incurs additional costs to households, ${ }^{14}$ and overburdens health care systems. ${ }^{15}$ Thus, routine screening and early detections is a current global approach to mitigate the progression of diabetes mellitus. ${ }^{16}$

Early diagnosis and intervention of DM have a massive benefit to at risk individuals through preventing or delaying the onset of DM and reduce the burden associated with subsequent complications. This is only possible when pieces of evidence are available on the extent and risks of DM. In this regard, limited studies conducted in different parts of the country; have neither reported the relationship between diabetes and lipid profile nor comprehensively addressed behavioral characteristics, physical measurements, and lipid profile. Therefore, this study aimed to determine unrecognized DM and its relationship with behavioral characteristics, physical measurement, and lipid profile of Ethiopian adults. Such data would help to design evidence-based effective communitylevel DM prevention and control mechanisms.

\section{Patients and Methods}

\section{Study Design, Setting and Period}

A Community based cross-sectional study was conducted from June 17 to July 27, 2019, in Jimma Town. The town is found in Oromia Regional State, Southwest Ethiopia $352 \mathrm{~km}$ from capital city Addis Ababa.

\section{Population, Sample and Sample Technique}

Adults aged $\geq 18$ years who are resided in the town for at least six months preceding the study were considered as the study population. However, adults who have physical deformity (kyphosis, sclerosis), known DM patients, and pregnant women were excluded from this study. The sample size for this study was estimated by using single population proportion formula with the assumptions of $11.5 \%$ prevalence of undiagnosed DM in East Gojjam, Northwest Ethiopia, ${ }^{17} 95 \%$ confidence interval (CI), 3\% margin of error, $10 \%$ nonresponse rate and 2 design effect which yielded the final sample size of 955 .

Multi-stage sampling technique was employed; from 17 Kebeles (the lowest administrative structure in Ethiopia) of the town, six Kebeles were randomly selected. Then, the sample was allocated to the selected Kebeles in proportion to the total number of households in each Kebele, who were selected systematically by using a list of households as a sampling frame. For households with more than one eligible study subjects, lottery method was used to select the participants.

\section{Data Collection and Measurements}

Data were collected using the WHO STEPS Questionnaire $^{18}$ adapted to the local context based on the study objectives. The data collection tool was initially prepared in English and translated to the local languages Afaan Oromo and Amharic. The questionnaire was pretested in Agaro town before two weeks applying it to the final data collection which has similar characteristics with study area to detect any possible problems in the flow of the questionnaires, gauge the length of time required for interviews, feasibility, and the clarity of the language used. A stepwise approach to collect socio-demographic data, behavioral characteristic, physical measurements, and biochemical measurements were done. Data were collected by seven trained professional nurses who were recruited 
based on their qualifications, prior experience of data collection, and abilities to speak the local languages. The data collectors were trained for four days before the actual data collection on interviewing approach, sample taking, anthropometric measurement, and data recording. All interviews and measurements were done with close supervision of the research team.

\section{Demographic and Behavioral Characteristics}

Data on socio-demographic and behavioral characteristics were collected through face-to-face interviews using an interviewer-administered questionnaire. Socio-demographic data include age, sex, educational level, marital status, occupational status, and income; behavioral characteristics including alcohol consumption, smoking habit, Khat chewing, and physical activity. Physical activity was measured by using the WHO physical activity questionnaire. Based on this, an adult person should do at least 150 minutes of moderate-intensity work or 75 minutes of vigorous-intensity work per week. If the self-reported physical activity did not fit with the WHO recommendation, participants were categorized as physically inactive. Sedentary behavior was measured by asking about the time spent sitting during a typical week. The responses were classified as $<4$ hours/day and $\geq 4$ hours/day. ${ }^{19}$

Khat chewing and tobacco use were defined as selfreported current chewing of Khat and use of smoked tobacco or smokeless tobacco products respectively. Alcohol use defined as a person who consumed alcohol in the past 12 months. $^{20}$

\section{Physical Measurements}

In this step, the height and weight needed to calculate body mass index (BMI), waist circumference, waist to hip ratio, and blood pressure were taken. The height of the study participants was measured to the nearest $0.1 \mathrm{~cm}$ using a stadiometer (Seca Germany) with the subjects positioned at the Frankfurt Plane and the four points (heel, calf, buttocks, and shoulder) touching the vertical stand and their shoes taken off. Before starting the measurements, the stadiometer was checked using calibration rods. Weights were measured using a digital weight scale to the nearest $0.1 \mathrm{~kg}$ with the subjects wearing light closes and shoes taken off. The validity of the scale was checked using an object of a known weight every morning and between the measurements. Then, BMI was calculated by weight in kilograms divided by height in meters squared formula. $\mathrm{BMI}<18.5 \mathrm{~kg} / \mathrm{m} 2$ is considered as underweight,
$18.5-24.9 \mathrm{~kg} / \mathrm{m} 2$ as normal, $25-29.9 \mathrm{~kg} / \mathrm{m} 2$ as overweight and $\geq 30 \mathrm{~kg} / \mathrm{m} 2$ as obese.

Waist circumferences (WC) were measured at the midway between the lowest costal margin at the midclavicular line and the anterior superior iliac spine using fixed tension tape. WC values $>94 \mathrm{~cm}$ for men and $>80 \mathrm{~cm}$ for women were considered high according to the WHO recommendation. $^{21}$

Blood pressure (BP) was taken in a sitting position from the right arm. It was measured in triplicate using an Aneroid Sphygmomanometer with small, medium, and large cuff size, ${ }^{22}$ as fit to the subjects after five minutes of rest. The subsequent measurements were done five minutes apart. According to the WHO recommendation, the mean systolic and diastolic blood pressures were considered for analysis. Prehypertension is defined as systolic BP of 120-139 and diastolic BP $80-89 \mathrm{mmHg}$. Hypertension is defined as systolic BP of $\geq 140 \mathrm{mmHg}$ and/or diastolic BP of $\geq 90 \mathrm{mmHg}^{23}$

\section{Biochemical Measurements}

Random and fasting blood glucose, high-density lipoprotein (HDL), low-density lipoprotein (LDL), triglyceride (TG), and total cholesterol (TC) level measurements were done. The laboratory parameters were determined according to the laboratory standard operating procedures. Five (5) $\mathrm{mL}$ venous blood was collected to determine participants' random and fasting blood glucose levels and lipid profiles. Serum was carried out in ABX Pentra 400 Automated Chemistry Machine (Horiba ABX SAS, 34184 Montpellier, France) at Jimma Medical Center (JMC) Clinical chemistry core laboratory to determine random and fasting blood glucose and lipid profile. Low-density lipoprotein level was calculated by using Freidwald formula. ${ }^{24}$ The diagnosis of DM was based on the American Diabetes Association and IDF diabetes mellitus classification criteria with fasting blood glucose (FBG) of $\geq 126 \mathrm{mg} / \mathrm{dl}$ and random blood glucose (RBG) of $\geq 200 \mathrm{mg} / \mathrm{dl}$ being considered as positive for DM; Pre-diabetes, FBG: $\leq 100 \mathrm{mg} / \mathrm{dl}$ to $<126 \mathrm{mg} / \mathrm{dl}$ and RBG: $\leq 140 \mathrm{mg} / \mathrm{dl}$ to $<199 \mathrm{mg} / \mathrm{dl}^{25,26}$

$\mathrm{TC} \geq 200 \mathrm{mg} / \mathrm{dl}$ considered as high and if it is $<200 \mathrm{mg} / \mathrm{dl}$ as normal; the optimal level of LDL is less than $100 \mathrm{mg} / \mathrm{dl}$ otherwise it is defined as high. Triglycerides level is considered as normal when it was less than $150 \mathrm{mg} / \mathrm{dl}$ and HDL is considered as desirable if it is $>40 \mathrm{mg} / \mathrm{dl}$ for men and $>50 \mathrm{mg} / \mathrm{dl}$ for women, otherwise, it was classified as low. ${ }^{27}$ A laboratory technologist, who does not know the participant's history or other measurements, determined all laboratory values. 


\section{Data Processing and Analysis}

First, the data were checked for completeness and consistency and double entered into EPI data software version 3.1 and exported to SPSS version 21 for analysis. Descriptive statistics were used to summarize the background characteristics of study participants. Bivariate and multivariable analyses were used to assess the association between explanatory variables and the outcome variable. All explanatory variables with $p$-values $\leq 0.25$ in the bivariate analysis were entered into a multivariable logistic regression model to assess the independent predictors of DM. The strength of the associations between predictor variables and DM were measured using adjusted odds ratios (AORs) with their corresponding $95 \%$ confidence intervals (CIs) at P-value $\leq 0.05$.

\section{Results}

\section{Socio-Demographic Characteristics}

A total of 915 adults with a response rate of $95.8 \%$ participated in the study. The mean age of the study participants was $38.4 \pm 13.5$ years. Males accounted for $52.0 \%$ and $71.5 \%$ of the study participants were married. About $84 \%$ of the study population had some levels of formal education (Table 1).

\section{Behavioral Characteristics}

More than one third (35.1\%) of the participants were chewing Khat during the study period. Moreover, $16.7 \%$ and $7.9 \%$ of participants were current alcohol drinkers and smokers respectively. Only $34.0 \%$ of the participants could be considered as physically active and $58.0 \%$ spent more than 4 hours per day by sitting or reclining (Table 2).

\section{Physical and Biochemical Measurements}

More than one-fourth $(27.8 \%)$ of the participants were overweight or obese with a BMI of $\geq 25 \mathrm{~kg} / \mathrm{m}^{2}$ and $21.2 \%$ of the respondents had unrecognized hypertension. On other hand, $23.7 \%$ had central obesity based on their waist circumference and $13.8 \%$ of the participants had total cholesterol more than $200 \mathrm{mg} / \mathrm{dl}$ (Table 3).

\section{Prevalence of Unrecognized Diabetes Mellitus}

The prevalence of unrecognized diabetes mellitus was $3.1 \%$ (95\% CI; $2.0-4.4$ ), whereas $14.8 \%$ (95\% CI; $12.5-$ 17.2) of the study participants had prediabetes.
Table I Socio-Demographic Characteristics of Recruited Subjects $(n=915)$

\begin{tabular}{|c|c|c|c|}
\hline \multicolumn{2}{|l|}{ Variables } & \multirow{3}{*}{$\begin{array}{l}\text { Frequency } \\
476 \\
439\end{array}$} & \multirow{3}{*}{$\begin{array}{l}\text { Percent (\%) } \\
52.0 \\
48.0\end{array}$} \\
\hline Sex & Male & & \\
\hline & Female & & \\
\hline \multirow[t]{2}{*}{ Age group (years) } & $<35$ & 403 & 44.0 \\
\hline & $\geq 35$ & 512 & 56.0 \\
\hline \multirow[t]{6}{*}{ Educational status } & Illiterate & 150 & 16.4 \\
\hline & Primary & 377 & 41.2 \\
\hline & school & & \\
\hline & Secondary & 213 & 23.3 \\
\hline & school & & \\
\hline & Diploma and & 175 & 19.1 \\
\hline \multirow{5}{*}{ Marital status } & & & \\
\hline & Single & 130 & 14.2 \\
\hline & Married & 654 & 71.5 \\
\hline & Divorced/ & $|3|$ & 14.3 \\
\hline & Widowed & & \\
\hline \multirow[t]{3}{*}{ Occupation } & Unemployed & 316 & 34.5 \\
\hline & Employed & 316 & 34.5 \\
\hline & Private work & 283 & 31.0 \\
\hline \multirow[t]{3}{*}{ Family size } & $\mathrm{I}-2$ & $|5|$ & 16.5 \\
\hline & $3-5$ & 483 & 52.8 \\
\hline & $>5$ & 281 & 30.7 \\
\hline \multirow{3}{*}{$\begin{array}{l}\text { Annual Income } \\
\text { (Ethiopian birr) }\end{array}$} & $\leq 10,000$ & 374 & 40.9 \\
\hline & $10,001-49,999$ & 446 & 48.7 \\
\hline & $\geq 50,000$ & 95 & 10.4 \\
\hline
\end{tabular}

\section{Factors Associated with Unrecognized Diabetes Mellitus}

In the bivariate analysis, sex, age, alcohol drinking, BMI, waist circumference, physical activity, triglyceride, and total cholesterol were found to be significantly associated with DM.

Independent risk factors associated with unrecognized $\mathrm{DM}$ on the multivariable logistic regression analysis were sex, age, physical activity, and waist circumference. Males were about three times $(\mathrm{AOR}=2.94,95 \% \mathrm{CI}: 1.19,7.29)$ more likely to have unrecognized DM than females. The risk of unrecognized DM was more than three times $(\mathrm{AOR}=$ $3.45,95 \%$ CI: $1.16,10.27)$ higher in those study participants age 35 years and above compared to those in the age group below 35 years. The risk of developing DM among participants who perform sufficient physical activities was $86 \%$ $(\mathrm{AOR}=0.14,95 \% \mathrm{CI}: 0.03,0.58)$ less likely compared to those who perform insufficient physical activities. Moreover, the study participants with high waist 
Table 2 Behavioral Characteristics of Sampled Adults $(n=9 \mid 5)$

\begin{tabular}{|l|l|l|l|}
\hline \multicolumn{2}{|l|}{ Variables } & Frequency & Percent (\%) \\
\hline Current smoking & Yes & 72 & 7.9 \\
& No & 843 & 92.1 \\
\hline Alcohol drinking & Yes & 153 & 16.7 \\
& No & 762 & 83.3 \\
\hline $\begin{array}{l}\text { Current khat } \\
\text { chewing }\end{array}$ & Yes & 321 & 35.1 \\
\hline Level of physical & No & 594 & 64.9 \\
activity & Sufficient & 311 & 66.0 \\
\hline Sedentary behavior & $<4$ hours/day & 384 & 42.0 \\
& $\geq 4$ hours/day & 531 & 58.0 \\
\hline
\end{tabular}

Table 3 Physical and Biochemical Characteristics $(n=9 \mid 5)$

\begin{tabular}{|l|l|l|l|}
\hline \multicolumn{2}{|l|}{ Variables } & Frequency & $\begin{array}{l}\text { Percent } \\
\text { (\%) }\end{array}$ \\
\hline Body mass index & $\begin{array}{l}\text { Underweight } \\
\text { Normal } \\
\text { Overweight } \\
\text { Obese }\end{array}$ & $\begin{array}{l}135 \\
525\end{array}$ & $\begin{array}{l}177 \\
78\end{array}$ \\
& No & 72.4 \\
& Yes & 19.3 \\
\hline Unrecognized \\
hypertension & Normal & 698 & 78.8 \\
\hline Waist circumference & High & 217 & 21.2 \\
\hline Waist to hip ratio & Normal & 243 & 76.3 \\
& High & 672 & 23.7 \\
\hline Total cholesterol & $<200 \mathrm{mg} / \mathrm{dl}$ & 789 & 83.4 \\
& $\geq 200 \mathrm{mg} / \mathrm{dl}$ & 126 & 13.8 \\
\hline Triglyceride & $<150 \mathrm{mg} / \mathrm{dl}$ & 660 & 72.1 \\
& $\geq 150 \mathrm{mg} / \mathrm{dl}$ & 255 & 27.9 \\
\hline HDL cholesterol & Low & 455 & 49.7 \\
& Normal & 460 & 50.3 \\
\hline LDL cholesterol & $<100 \mathrm{mg} / \mathrm{dl}$ & 604 & 66.0 \\
& $\geq 100 \mathrm{mg} / \mathrm{dl}$ & 311 & 34.0 \\
\hline
\end{tabular}

Abbreviations: HDL, high-density lipoprotein; LDL, low-density lipoprotein.

circumference were $4.21(\mathrm{AOR}=4.21,95 \% \mathrm{CI}: 1.72,10.33)$ times more likely to have unrecognized DM compared to those who had a normal waist circumference (Table 4).

\section{Discussion}

The current study revealed that the overall prevalence of unrecognized DM among respondents was $3.1 \%$. This finding is comparable with findings of studies done in
Indonesia (3.5\%), ${ }^{28}$ Northwest Nigeria $(4.3 \%),{ }^{29}$ Gilgel Gibe Field Research Center, Ethiopia (3.8\%), ${ }^{30}$ and Dire Dawa town $(3.3 \%) .{ }^{31}$ However, the current study found a relatively higher proportion of unrecognized DM than the study conducted in Kenya (2.4\%), ${ }^{16}$ Benin (1.4\%), ${ }^{32}$ Southern Ethiopia, Sidama zone $(1.9 \%),{ }^{33}$ and rural Koladiba town $(2.3 \%) .{ }^{34}$ This discrepancy might be due to differences in socio-demographic characteristics of study participants, study setting, and sample size. Compared to studies conducted in Kenya, Benin, and Sidama zone, Ethiopia, the present study purely conducted among urban residents where the risk of diabetes mellitus is relatively high. The different levels of economic development and urbanization cause changes in lifestyle which includes a low level of physical activities, increase sedentary behavior and nutritional transition, higher intake of unhealthy foods that are rich in calories. Moreover, studies done in rural Koladiba town, Ethiopia has conducted relatively small samples compared to the current study. Thus, as the sample increases the chance of detecting unrecognized diabetes mellitus might be increased. Another reason for the discrepancy might be due to study participants in the current study exercising risky behaviors. For instance, about two-thirds $(66.0 \%)$ of them were physically inactive, $58 \%$ had sedentary behaviors and $35.1 \%$ had Khat chewing behavior, which could be the risk factor for DM.

On another hand, the risk of unrecognized DM was lower than studies done in Monastir City, Tunisia $(27.4 \%),{ }^{35}$ East Gojjam zone, Ethiopia $(11.5 \%),{ }^{17}$ and Pakistan $(26.3 \%) .{ }^{36}$ The difference might be due to disparity in genetic, lifestyle, and age group of the study population. The current study included adults 18 years of age and above, whereas the Tunisia study comprised an elderly population of 65 years and above, and in East Gojjam zone, Ethiopia included age 25 years and above. Hence, different pieces of evidence including our study supported that the risk of occurrence of DM was significantly higher among older age groups compared to younger age groups. ${ }^{17,33,37-40}$ Conversely, the increased prevalence of DM in Pakistan study might be due to the use of Oral Glucose Tolerance Test (OGTT) and HbA1c for diagnoses DM in addition to FBG and RBG which used in our study. This might be amplified the detection rate of diabetes mellitus in the case of Pakistan's study.

The present study revealed that the risk of unrecognized DM was significantly higher among males compared to females, which is consistent with other studies. ${ }^{30,41,42}$ Even though the reason for this difference is not clear, studies 
Table 4 Bivariate and Multivariate Regression Analysis to Identity Risk Factors Associated with Unrecognized Diabetes Mellitus $(n=915)$

\begin{tabular}{|c|c|c|c|c|}
\hline \multirow[t]{2}{*}{ Variables } & \multicolumn{2}{|c|}{ Unrecognized DM } & \multirow[t]{2}{*}{ COR, $95 \% \mathrm{Cl}$} & \multirow[t]{2}{*}{ AOR, $95 \% \mathrm{Cl}$} \\
\hline & Yes & No & & \\
\hline \multicolumn{5}{|l|}{ Sex } \\
\hline Female & 10 & 429 & 1 & I \\
\hline Male & 18 & 458 & $\mathrm{I} .67(0.77,3.69)$ & $2.94(1.19,7.29)^{\mathrm{a}}$ \\
\hline \multicolumn{5}{|l|}{ Age } \\
\hline$<35$ years & 4 & 399 & I & I \\
\hline$\geq 35$ years & 24 & 488 & $4.91(1.69,14.26)$ & $3.45(1.16,10.27)^{a}$ \\
\hline \multicolumn{5}{|c|}{ Alcohol consumption } \\
\hline Yes & 7 & 146 & 1 & \\
\hline No & 21 & 741 & $0.59(0.25,1.42)$ & \\
\hline \multicolumn{5}{|l|}{ Physical activity } \\
\hline Insufficient & 26 & 578 & 1 & 1 \\
\hline Sufficient & 2 & 309 & $0.14(0.03,0.61)$ & $0.14(0.03,0.58)^{b}$ \\
\hline \multicolumn{5}{|l|}{ BMI } \\
\hline$\leq 24.99 \mathrm{~kg} / \mathrm{m}^{2}$ & 16 & 644 & 1 & \\
\hline$\geq 25 \mathrm{~kg} / \mathrm{m}^{2}$ & 12 & 243 & $1.99(0.93,4.26)$ & \\
\hline \multicolumn{5}{|c|}{ Waist circumference } \\
\hline Normal & 15 & 683 & 1 & 1 \\
\hline High & 13 & 204 & $2.90(1.36,6.20)$ & $4.21(1.72,10.33)^{b}$ \\
\hline \multicolumn{5}{|l|}{ Total cholesterol } \\
\hline$<200 \mathrm{mg} / \mathrm{dl}$ & 22 & 767 & 1 & \\
\hline$\geq 200 \mathrm{mg} / \mathrm{dl}$ & 6 & 120 & $1.74(0.69,4.39)$ & \\
\hline \multicolumn{5}{|l|}{ Triglyceride } \\
\hline$<150 \mathrm{mg} / \mathrm{dl}$ & 17 & 643 & 1 & \\
\hline$\geq 150 \mathrm{mg} / \mathrm{dl}$ & 11 & 244 & I.7I $(0.79,3.69)$ & \\
\hline
\end{tabular}

Notes: ${ }^{\mathrm{a}} \mathrm{P}<0.05 ;{ }^{\mathrm{b}} \mathrm{P}<0.005$.

suggested that males have increased visceral fat deposition, which may cause insulin resistance and hyperglycemia. This might be contributing to an increased risk of diabetes development. $^{43,44}$ This also supported with current study; $81.6 \%$ of larger waist circumference was from male participants. Besides, this disparity likely due to differences in lifestyle (decreased physical activity, increased high-calorie intake, high sugar, and high fat) and work-related stress. ${ }^{45}$

The recent study also found that the risk of unrecognized DM was increased with advancing age. This is in line with previous studies conducted around the world. $^{16,17,31,37,46-48}$ This is most likely due to a decline in lean body mass and an increase in body fat, particularly visceral adiposity which may contribute to the development of insulin resistance, the tendency of low physical activity, and increased body weight. ${ }^{44,49}$ This also supplemented with the present study. Of the total participants who had central obesity (high waist circumference), $73.7 \%$ were in the age group 35 years and above. Moreover, pancreatic $\beta$-cell mass in adults exists in an active state such that the cells can undergo compensatory changes to maintain circulating glucose concentrations within a narrow physiologic range. While, as age increases the capacity of pancreatic $\beta-$ cells regeneration is decreased and enhances sensitivity to apoptosis. Consequently, this causes a decrease in insulin sensitivity and the inadequate response of $\beta$-cell functional mass when there is insulin resistance. ${ }^{50}$

Consistent with findings of previous studies, ${ }^{30,39,40,46,47}$ the current study revealed sufficient physical activities reduce the risk of unrecognized DM. This is because physical activities minimize the risk of hyperglycemia through increasing insulin-stimulated glycogen synthesis, enhancing muscle glucose uptake, making the muscle being more 
sensitive to the actions of insulin and it balances the average caloric intake and expenditure by the body cells. ${ }^{51}$

Similar to the previous research reports, ${ }^{28,33,37,52,53}$ the occurrence of unrecognized DM is higher among adults with central obesity (larger waist circumference). This might be because, in individuals with expanded abdominal fat accumulation, adipose tissue releases highly active hormones (adipokines), increased amount of free fatty acids, glycerol, pro-inflammatory cytokines, and other factors that are involved in the development of insulin resistance and impairment of glucose homeostasis. ${ }^{54}$

Even though the risk of unrecognized DM was not significantly associated with the lipid profiles in the current study, evidence showed that the elevated levels of TGs, TC, and LDL cholesterol and low level of HDL cholesterol had a high risk for developing DM. This is because the situation may lead to dysregulation in glucose metabolism by inducing insulin resistance and beta-cell dysfunction. ${ }^{55}$

The strengths of this study were its being community based and involving an adequate sample. While the major limitation of the study is that only FBG and RBG were used to diagnose DM, which might underestimate the prevalence of unrecognized DM, and we suggest that using $\mathrm{HbAlc}$ for future similar studies. The study also did not consider acute and chronic illnesses which may affect the blood sugar level. In addition, the study did not addresses psychological factors apart from substance use which might be risk factors for DM.

\section{Conclusion}

The prevalence of unrecognized diabetes mellitus among adults Jimma town was relatively high. Male sex, advanced age, physical inactivity, and central obesity (high waist circumference) were found to be predictors of unrecognized DM. Thus, awareness creation activities targeting adults should be devised regarding to regular physical activity and maintaining normal body weight. Additionally, screening of DM should be promoted for early detection, prevention, and treatment.

\section{Abbreviations}

AOR, adjusted odds ratio; BMI, body mass index; BP, blood pressure; $\mathrm{CI}$, confidence interval; $\mathrm{COR}$, crude odds ratio; DM, diabetes mellitus: FBS, fasting blood sugar; HDL, highdensity lipoprotein; IDF, International Diabetes Federation; JMC, Jimma Medical Center; LDL, low-density lipoprotein; NCD, non-communicable diseases; OGTT, Oral Glucose
Tolerance Test; RBS, random blood sugar; TC, total cholesterol; TG, triglyceride; WC, waist circumference; WHO, World Health Organization.

\section{Data Sharing Statement}

The datasets used for the current study is available from the corresponding author upon reasonable request.

\section{Ethical Approval and Consent to Participate}

Ethical clearance was obtained from Jimma University, Institute of Health Ethical Review board. A letter of support was obtained from Jimma town and communicated to selected Kebele administrations. Besides, before data collection written informed consents was obtained from each study participant. All the participants' information was kept confidential using coding system. Participants identified with diabetes and pre-diabetes were advised and linked to nearby health facilities for further investigation and management.

\section{Acknowledgments}

Jimma University is greatly acknowledged for the financial support of the study. The authors are grateful to the study participants for taking their time to provide information. Research assistants are also appreciated for their immense contributions.

\section{Author Contributions}

All authors made substantial contributions to conception and design, acquisition of data, analysis and interpretation of data; took part in drafting the article or revising it critically for important intellectual content; gave final approval of the version to be published; and agree to be accountable for all aspects of the contents of the article.

\section{Disclosure}

The authors declare that they have no competing interests.

\section{References}

1. WHO. Definition, diagnosis and classification of Diabetes Mellitus and its complication: report of a WHO consultation. Part 1, Diagnosis and Classification of Diabetes Mellitus. Geneva: World Health Organization; 1999. Available from: https://www.staff.ncl.ac.uk/phi lip.home/who_dmg.pdf. Accessed May 21, 2020.

2. WHO. Global Health Risks: mortality and burden of disease attributable to selected major risks. Geneva: Switzerland; 2009. Available from: http://www.who.int/healthinfo/global_burden_disease/ GlobalHealthRisks_report_full.pdf. Accessed May 21, 2020. 
3. Baena-Díez JM, Peñafiel J, Subirana I, et al. Risk of cause-specific death in individuals with diabetes: A competing risks analysis. Diabetes Care. 2016;39(11):1987-1995. doi:10.2337/dc16-0614

4. Motala A, Omar M. Diabetes in Africa: diabetes micro vascular and macro vascular disease in Africa. $J$ Cardiovasc Risk. 2003;10 (2):97-102. doi:10.1097/00043798-200304000-00002

5. Saeedi P, Petersohn I, Salpea P, et al. Global and regional diabetes prevalence estimates for 2019 and projections for 2030 and 2045: results from the International Diabetes Federation Diabetes Atlas, 9th edition. Diabetes Res Clin Pract. 2019;157:107843. doi:10.1016/j. diabres.2019.107843.

6. Mathers CD, Loncar D. Projections of global mortality and burden of disease from 2002 to 2030. PLoS Med. 2006;3(11):2011-2030. doi:10.1371/journal.pmed.0030442

7. IDF. IDF Diabetes Atlas: prevalence of diabetes (20-79 years), Ninth edition; 2019. Available from: https://diabetesatlas.org/upload/ resources/2019/2019_regional_factsheet.pdf. Accessed August 6, 2020 .

8. Whiting DR, Guariguata L, Weil C, Shaw J. IDF Diabetes Atlas: global estimates of the prevalence of diabetes for 2011 and 2030. Diabetes Res Clin Pract. 2011;94(3):311-321. doi:10.1016/j. diabres.2011.10.029

9. International Diabetes Federation. IDF Diabetes Atlas: Africa. 8th ed; 2017:140. Available from: https://www.idf.org/e-library/epidemiol ogy-research/diabetes-atlas.html. Accessed May 22, 2020.

10. Beagley J, Guariguata L, Weil CMA. Global estimates of undiagnosed diabetes in adults. Diabetes Res Clin Pract. 2014;103 (2):150-160. doi:10.1016/j.diabres.2013.11.001

11. Kiberenge MW, Ndegwa ZM, Njenga EW, Muchemi EW. Knowledge, attitude and practices related to diabetes among community members in four provinces in Kenya: a cross-sectional study. Pan Afr Med J. 2010;7(1):2.

12. Ismail H, Omar MA, Aqilah A, Hisham N, Aris T, Ambak R. Undiagnosed type 2 diabetes mellitus and its risk factors among Malaysians: national health and morbidity survey, 2011. Int J Public Health Res. 2016;6(1):677-684.

13. Zhou B, Yuan L, Hajifathalian K, et al. Worldwide trends in diabetes since 1980: a pooled analysis of 751 population-based studies with 4.4 million participants. Lancet. 2016;387(10027):1513-1530. doi:10.1016/S0140-6736(16)00618-8

14. Kankeu HT, Saksena P, Xu K, Evans DB. The financial burden from non-communicable diseases in low- and middle-income countries: A literature review. Health Res Policy Syst. 2013;11(1):1-12.

15. World health organization. The world health report - health systems financing: the path to universal coverage; 2010. Available from: https://www.rbfhealth.org/resource/world-health-report-healthsystems-financing-path-universal-coverage. Accessed May 22, 2020.

16. Mohamed SF, Mwangi M, Mutua MK, et al. Prevalence and factors associated with pre-diabetes and diabetes mellitus in Kenya: results from a national survey. BMC Public Health. 2018;18(Suppl):3. doi:10.1186/s12889-018-6053-x

17. Wondemagegn AT, Bizuayehu HM, Abie DD, Ayalneh GM, Tiruye TY, Tessema MT. Undiagnosed diabetes mellitus and related factors in East Gojjam (NW Ethiopia) in 2016: A community-based study. $J$ Public Health Res. 2017;6(1):18-23. doi:10.4081/jphr.2017.834

18. World Health Organization. The WHO Stepwise approach to Surveillance of non-communicable diseases (STEPS): non-communicable Diseases and Mental Health 20 Avenue Appia. 1211 Geneva 27, Switzerland; 2003. Available from: http://apps.who. int/iris/bitstream/handle/10665/43376/\%0A9241593830_eng.pdf? sequence $=1$ \&isAllowed $=y$. Accessed May 26, 2019.

19. WHO. Global Physical Activity Questionnaire (GPAQ) Analysis Guide [Internet]. Geneva: World Health Organization; 2012. Available from: http://scholar.google.com/scholar?hl=en\&btnG= Search\&q=intitle:Global \pm Physical \pm Activity \pm Questionnaire $\pm($ GPAQ) \pm Analysis \pm Guide\#1. Accessed May 22, 2020.
20. Lasebikan V, Ola BA, Ayinde OO. Effectiveness of alcohol, smoking, and substance involvement screening test-linked brief intervention on harmful and hazardous alcohol use in Nigerian semirural communities: A non-randomized intervention study. Front Psychiatry. 2017;8(50):1-7. doi:10.3389/fpsyt.2017.00050

21. World Health Organisation. Waist Circumference and Waist-Hip Ratio. Report of a WHO Expert Consultation. Geneva, 8-11 December 2008; 2011.

22. Frese EM, Fick A, Sadowsky SH. Blood pressure measurement guidelines for physical therapists. Cardiopulm Phys Ther J. 2011;22 (2):5-12. doi:10.1097/01823246-201122020-00002

23. Chobanian AV, Bakris GL, Black HR, et al. The seventh report of the joint national committee on prevention, detection, evaluation, and treatment of high blood pressure: the JNC 7 report. $\mathrm{J} \mathrm{Am} \mathrm{Med}$ Assoc. 2003;289(19):2560-2572. doi:10.1001/jama.289.19.2560

24. Hata YNK. Application of Friedewald's LDL-cholesterol estimation formula to serum lipids in the Japanese population. Jpn Circ J. 1986;50(12):1191-2000. doi:10.1253/jcj.50.1191

25. American Diabetes Association. Diagnosis and classification of diabetes mellitus. Diabetes Care. 2014;37(1):S81-S90. doi:10.2337/ dc14-S081

26. International Diabetes Federation. IDF Clinical Practice Recommendations for managing Type 2 Diabetes in Primary Care International Diabetes Federation - 2017; 2017:1-32.

27. Target Lipid Recommendations (ATP-IV). National Cholesterol Education Program Expert Panel on Detection, Evaluation, and Treatment of High Blood Cholesterol in Adults; 2012. Available from: https://connect.springerpub.com/content/reference-book/9780-8261-7934-0/back-matter/part02/back-matter/bmatter4. Accessed May 12, 2020.

28. Mihardja L, Soetrisno U, Soegondo S. Prevalence and clinical profile of diabetes mellitus in productive aged urban Indonesians. J Diabetes Investig. 2014;5(5):507-512. doi:10.1111/jdi.12177

29. Adebimpe WO, Faremi AO, Hassan AWO. Prevalence of diabetes mellitus and its risk factors among the suburban population of Northwest Nigeria Anas. Sahel Med J. 2018;21(2):99-103.

30. Seifu W, Kifle Woldemichael BT. Prevalence and risk factors for diabetes mellitus and impaired fasting glucose among adults aged 15-64 years in Gilgel Gibe Field Research Center, Southwest Ethiopia, 2013: through a who step wise approach. MOJ Public Health. 2015;2(5):4-11. doi:10.15406/mojph.2015.02.00035

31. Ayele BH, Shore H, Shunu A, Mengesha MM. Diagnosed and undiagnosed Diabetes mellitus among urban adults: a population based cross-sectional study. 2019:1-24. doi:10.1101/532705

32. Kpozehouen A, Djrolo F, Sossa CJ, et al. Prevalence and associated factors of diabetes mellitus in Benin. Open J Epidemiol. 2015;05 (03):163-171. doi:10.4236/ojepi.2015.53021

33. Zekewos A, Loha E, Egeno T, Wubshet K, Merga Z. Prevalence of diabetes mellitus and associated factors in southern Ethiopia: a community based study. Ethiop J Health Sci. 2018;28(4):451-460.

34. Worede A, Alemu S, Gelaw YA, Abebe M. The prevalence of impaired fasting glucose and undiagnosed diabetes mellitus and associated risk factors among adults living in a rural Koladiba town, northwest Ethiopia. BMC Res Notes. 2017;10(1):1-7. doi:10.1186/s13104-017-2571-3

35. Hammami S, Mehri S, Hajem S, Koubaa N, Souid H, Hammami M. Prevalence of diabetes mellitus among non-institutionalized elderly in Monastir City. BMC Endocr Disord. 2012;12. doi:10.1186/14726823-12-15

36. Basit A, Fawwad A, Qureshi H, et al. Prevalence of diabetes, prediabetes and associated risk factors: second National Diabetes Survey of Pakistan (NDSP), 2016-2017. BMJ Open. 2018;8(8):e020961. doi:10.1136/bmjopen-2017-020961

37. Hu M, Wan Y, Yu L, et al. Prevalence, awareness and associated risk factors of diabetes among Adults in Xi'an, China. Sci Rep. 2017;7 (1):1-9. 
38. Dereje N, Earsido A, Temam L, Abebe A. Prevalence and associated factors of diabetes mellitus in Hosanna Town, Southern Ethiopia. Ann Glob Health. 2020;86(1):18. doi:10.5334/aogh.2663

39. Asamoah-Boaheng M, Sarfo-Kantanka O, Tuffour AB, Eghan B, Mbanya JC. Prevalence and risk factors for diabetes mellitus among adults in Ghana: A systematic review and meta-analysis. Int Health. 2019;11(2):83-92. doi:10.1093/inthealth/ihy067

40. Uloko AE, Musa BM, Ramalan MA, et al. Prevalence and risk factors for diabetes mellitus in Nigeria: a systematic review and meta-analysis. Diabetes Ther. 2018;9(3):1307-1316. doi:10.1007/s13300-018-0441-1

41. Wang R, Zhang P, Li Z, et al. The prevalence of pre-diabetes and diabetes and their associated factors in Northeast China: a cross-sectional study. Sci Rep. 2019;9(1):1-8.

42. Tripura K, Nag K, Karmakar N, Datta A, Bhattacharjee P. A cross sectional study on the prevalence of diabetes mellitus among adult population in a peri-urban area of West Tripura, India. Int J Res Med Sci. 2019;7(3):843. doi:10.18203/2320-6012.ijrms20190934

43. Tramunt B, Smati S, Grandgeorge N, et al. Sex differences in metabolic regulation and diabetes susceptibility. Diabetologia. 2020;63 (3):453-461. doi:10.1007/s00125-019-05040-3

44. Nordström A, Hadrévi J, Olsson T, Franks PW, Nordström P. Higher prevalence of type 2 diabetes in men than in women is associated with differences in visceral fat mass. J Clin Endocrinol Metab. 2016;101(10):3740-3746. doi:10.1210/jc.2016-1915

45. Yang W, Lu J, Weng J, et al. Prevalence of diabetes among men and women in China. $N$ Engl $J$ Med. 2010;362(12):1090-1101. doi:10.1056/NEJMoa0908292

46. Nithesh Kumar K, Katkuri S, Ramyacharitha I. A study to assess prevalence of diabetes mellitus and its associated risk factors among adult residents of rural Khammam. Int J Community Med Public Health. 2018;5(4):1360-1365. doi:10.18203/2394-6040.ijcmph20180985
47. Abebe SM, Berhane Y, Worku A, Assefa A. Diabetes mellitus in North West Ethiopia: A community based study. BMC Public Health. 2014;14(1):7-9. doi:10.1186/1471-2458-14-97

48. Animaw W, Seyoum Y. Increasing prevalence of diabetes mellitus in a developing country and its related factors. PLoS One. 2017;12 (11):1-11. doi:10.1371/journal.pone.0187670

49. Kirkman MS, Briscoe VJ, Clark N, et al. Diabetes in older adults. Diabetes Care. 2012;35(12):2650-2664. doi:10.2337/dc12-1801

50. Lee PG, Halter JB. The pathophysiology of hyperglycemia in older adults: clinical considerations. Diabetes Care. 2017;40(4):444-452. doi:10.2337/dc16-1732

51. Goodyear LJ, Kahn BB. Exercise, glucose transport, and insulin sensitivity. Annu Rev Med. 1998;49:235-261. doi:10.1146/annurev. med.49.1.235

52. Aynalem SB, Zeleke AJ. Prevalence of diabetes mellitus and its risk factors among individuals aged 15 years and above in Mizan-Aman Town, Southwest Ethiopia, 2016: a cross sectional study. Int J Endocrinol. 2018;2018.

53. Bantie GM, Wondaye AA, Arike EB, et al. Prevalence of undiagnosed diabetes mellitus and associated factors among adult residents of Bahir Dar city, northwest Ethiopia: a community-based cross-sectional study. BMJ Open. 2019;9(10):1-7. doi:10.1136/bmjopen-2019-030158

54. Kahn SE, Hull RL, Utzschneider KM. Mechanism's linking obesity to insulin resistance and type 2 diabetes. Nature. 2006;444 (7121):840-846. doi:10.1038/nature05482

55. Bitzur R, Cohen H, Kamari Y, Shaish A, Harats D. Triglycerides and HDL cholesterol: stars or second leads in diabetes? Diabetes Care. 2009;32(2):373-377. doi:10.2337/dc09-S343

Diabetes, Metabolic Syndrome and Obesity: Targets and Therapy

Dovepress

\section{Publish your work in this journal}

Diabetes, Metabolic Syndrome and Obesity: Targets and Therapy is an international, peer-reviewed open-access journal committed to the rapid publication of the latest laboratory and clinical findings in the fields of diabetes, metabolic syndrome and obesity research. Original research, review, case reports, hypothesis formation, expert opinion and commentaries are all considered for publication. The manuscript management system is completely online and includes a very quick and fair peer-review system, which is all easy to use. Visit http://www.dovepress.com/testimonials.php to read real quotes from published authors.

Submit your manuscript here: https://www.dovepress.com/diabetes-metabolic-syndrome-and-obesity-targets-and-therapy-journal 